\title{
De la concentración del poder en los grupos fundadores a la distribución entre grupos emergentes. La democracia interna del Partido Acción Nacional en México (1939-2012)
}

\author{
From power concentration in the founding \\ emerging groups. Internal democracy of the \\ National Action Party in México (1939-2012)
}

\section{Alberto Espejel Espinoza}

\section{Resumen}

El Partido Acción Nacional superó los setenta años de existencia. Pese a esto, poco se ha dicho sobre la democracia interna de la organización, usualmente se conserva la idea de su carácter elitista. No obstante, poco se ha indagado sobre la evolución del partido a lo largo de su vida. Este trabajo caracteriza la democracia interna del partido, centrándose en las dimensiones de participación, competencia y representación. Se concluye sosteniendo el cambio que sufrió el partido de una situación donde la élite nacional concentraba al poder (1939-1990) a una donde se fragmentó entre diversos actores (poderes estatales, funciones de gobierno y partido) (1993-2012), fruto de los triunfos electores y la, consecuente, obtención de funciones de gobierno (década de los noventa).

\section{Palabras clave}

Selección de Dirigentes y Candidatos; PAN; Democracia Interna; Partidos Políticos.

\begin{abstract}
The National Action Party reached more than seventy years of existence. In spite of this, little has been said about this organization internal democracy. In a general way the idea that prevails is that of being of an elitist nature. However, few efforts have been undertaken to examine the long evolution life of the party. This paper characterizes the party's internal democracy highlighting the participation, competence and representative dimensions. The article concludes arguing that the change the party undertook from a situation where the national elite detained the political power (1939-1990) to one where it fragmented into several actors (state power, governmental and party's functions) (1990-1992), as result of the electoral victories and the resulting obtention of governmental functions (in the ninetes).
\end{abstract}

\section{Keywords}

Recruiting of Candidates; PAN; Internal Democracy; Political Parties. 


\section{Introducción}

El Partido Acción Nacional (PAN) es el segundo partido más antiguo de México, surgió en 1939 y estuvo durante casi 50 años en una posición marginal en el sistema de partidos hegemónico dominado por el Partido Revolucionario Institucional (PRI). Pese a su marginalidad, el PAN se caracterizó por ser un partido crítico a los gobiernos priístas. Al respecto, son reconocidas su énfasis en la función pública, su crítica al estado intervencionista, la defensa de la descentralización administrativa, entre otras banderas que enarboló desde su posición marginal.

Los triunfos electorales importantes vendrían en la década de los noventa, Acción Nacional se asentaría como partido en el poder y con ello dejaría de ser una oposición marginal. Al tiempo que el PRI comenzaba a perder posiciones de poder frente a los principales partidos opositores: el PAN y el Partido de la Revolución Democrática (PRD) que surgió en 1989. La década de los noventa significó el avance opositor en detrimento del PRI, dicho proceso tuvo un momento significativo en el año 2000 en que Acción Nacional gana la Presidencia de México. En ese entonces, se confirmaba la alternancia, pero también la existencia de un sistema de partidos que tiende a consolidar una correlación de fuerzas tripartidista a nivel nacional (PAN, PRI y PRD). Recientemente, Acción Nacional perdió la Presidencia de México que ocupó de 2000 a 2012, siendo el único partido en México que la ha detentado además del PRI.

El PAN ha sido marcado como un partido elitista, sin embargo dicha impresión no permite apreciar los cambios que ha sufrido respecto a su democracia interna, los cuales han sido amplios sobre todo a raíz de que comenzó a obtener triunfos electorales importantes a nivel estatal y, con ello, funciones de gobierno (1980-2000).

Pocos trabajos han abordado al PAN y su democracia interna, antes bien han estudiado un par de indicadores en un lapso breve (REVELES, 2005; ALARCÓN y FREIDENBERG, 2007). Son escasos los estudios de largo alcance, salvo los de quienes se interesan por la institucionalización del partido (LOAEZA, 1999; REVELES, 2002; REYNOSO, 2007 y 2009). Así, el presente trabajo caracteriza la democracia interna del PAN desde su génesis (1939) hasta la actualidad, por lo cual también se explora qué ha cambiado (1990-2012) y el porqué del cambio.

Para poder caracterizar la democracia interna del PAN es necesario responder a las siguientes interrogantes: ¿qué actores se dieron cita en la génesis y cuál de ellos dominó?, ¿cuál fue la huella que dejó esto en el desarrollo del partido en términos de la democracia interna? y ¿por qué varió la democracia interna y hacia dónde fue ese cambio?

En primera instancia se presentan los trazos teóricos (qué se entiende por democracia interna y cuáles son sus dimensiones e indicadores), en segundo lugar se presenta la primera etapa en la cual el poder se concentró en la élite nacional 
(1939-1990), en tercer lugar se muestra el detonador del cambio en la democracia interna (los triunfos electorales del PAN y la obtención de funciones de gobierno) $\mathrm{y}$, finalmente, se muestra la segunda etapa donde diversos actores (élite nacional, subnacional y gobierno) detentan el poder (1993-2012) ${ }^{1}$.

\section{Trazos teóricos-metodológicos}

En este apartado corresponde observar dos cuestiones, qué se entiende por democracia interna y dónde observarla. El interés por la democracia interna deriva de los excelentes trabajos en torno al funcionamiento real de los partidos que denunciaban la creación de oligarquías cerradas al interior de los partidos políticos (MICHELS, 1983; OSTROGORSKI, 1982). Empero, definir democracia interna, incluso hoy día, no es tarea fácil. Si hubiese una teoría de la democracia aceptada y si el lenguaje fuera utilizado de manera uniforme por todos, sería sencillo conceptuar el término democracia interna; sin embargo, dado que no es así, la complicación subsiste.

Aquí se asume que la democracia interna es una forma de organización que se diferencia de otras por la distribución del poder, es decir, por la capacidad de que la mayoría tome decisiones y se encuentre representada (NAVARRO, 1999; SCARROW, 2005). Siguiendo a Flavia Freidenberg, planteo que un partido deberá cumplir con varias condiciones para poder ser considerado democrático (FREIDENBERG, 2009). Al respecto, las dimensiones de interés son: 1) participación $\left.^{2}, 2\right)$ competencia $^{3}$ y 3) representación ${ }^{4}$. Por lo anterior, un partido

\footnotetext{
${ }^{1}$ En la medida de que el cambio en la democracia interna se relaciona con los triunfos electorales del PAN. La primera etapa se relaciona con la ausencia de triunfos relevantes, etapa que va de 1939 a fines de la década de los ochenta; mientras que la etapa que va de 1993 a 2012 en la cual Acción Nacional obtuvo sus mejores resultados electorales.

${ }^{2}$ Refiere a la participación en las principales decisiones del partido. Puede ir desde un exclusivo grupo que toma las principales decisiones, hasta un extremo donde estaría la participación de toda la militancia en las decisiones clave. Por ende, un partido será más democrático en la medida en que en sus procesos de selección participe mayor cantidad de miembros del partido. La pregunta que encierra esta dimensión es: ¿quién o quiénes deciden? Indicador: existen dos indicadores donde podemos observar esto, la selección de dirigentes nacionales y candidatos presidenciales. Ambos son los procesos más importantes de los partidos políticos y, generalmente, también son los más abordados en el tema de la democracia interna.

${ }^{3}$ Se relaciona con la existencia o no de varios contendientes y de la incertidumbre en un proceso electoral interno. Puede ir desde la existencia de un solo contendiente, a una situación donde un competidor no gana por sí solo en la primera ronda de votación o hasta un extremo donde dos o más contendientes tienen opciones reales de triunfo. En ese sentido. Así, un partido será más democrático en la medida que sus procesos electorales internos posean competitividad. La pregunta que encierra esta dimensión es: ¿posee opciones reales de triunfo más de un contendiente? Indicador: La selección de candidato presidencial y dirigente nacional son ámbitos donde podemos observar la competitividad.

${ }^{4}$ Refiere a la presencia de grupos y/o minorías desfavorecidos en los órganos ejecutivos del partido; desde un extremo donde no hay representación de grupos y minorías, hasta uno donde existe la proporcionalidad. La pregunta que encierra esta dimensión es: ¿quiénes están
} 
será más democrático cuando sus dirigentes nacionales y candidatos presidenciales sean electos por los miembros a través de elecciones competitivas, $\mathrm{y}$ cuando los órganos ejecutivos del partido integren a los diferentes grupos y minorías.

Ahora bien, habrá partidos más democráticos que otros en virtud del cumplimiento o no de las dimensiones antes planteadas, o dicho de otra forma en virtud de la distribución o concentración de poder. Ante la necesidad de caracterizar lo acontecido dentro de un partido, se debe considerar un continuum que va de los casos no democráticos a los democráticos. Siguiendo el trabajo de Susan Scarrow llamaré tendencias organizacionales a cada caso dentro del continuum, dichas tendencias no son exhaustivas ni excluyentes, pero proporcionan claridad y precisión para tener un mapa conceptual para el análisis empírico. Asimismo, son útiles para la caracterización de un partido en sus orígenes, así como para observar el cambio (SCARROW, 2005, p. 19). Por ende, con base en las dimensiones mencionadas planteo la existencia de cinco posibles tendencias organizacionales que muestran la democracia interna existente (o no).

1. Partido con líder dominante: El centro de poder puede ser un líder carismático, el dirigente o un gobernante que no promueve la participación y la competencia al seleccionar dirigentes y candidatos, antes bien los designa, al tiempo que el líder define la presencia de grupos en la dirección.

2. Partido de elite nacional: El locus de poder puede ser un grupo de notables, la dirigencia, miembros del grupo parlamentario, dirigentes de corporaciones o de fracciones (élite nacional) que reducen la participación y competencia, pues ellos deciden y compiten por la dirección y las candidaturas, aunado a que ellos integran los órganos ejecutivos del partido.

3. Partido de elites ampliado: El detentador de poder es un órgano deliberativo (Consejo Nacional) donde se encuentran presentes los poderes estatales (elite subnacional). Dicho órgano es quien alienta la competencia entre sus filas y quien elige candidatos y dirigentes, al tiempo que existe mayor representación porque los órganos ejecutivos se integran por representantes de la elite.

4. Partido representativo: El centro de poder es un órgano legislativo amplio (Congreso Nacional), el cual decide sobre la selección de dirigentes y candidatos, aunado a que permite mayor representación de grupos y minorías en los órganos ejecutivos.

5. Partido con democracia de bases: El locus de poder es la militancia, la cual selecciona a sus candidatos y dirigentes en elecciones competitivas,

representados en los órganos decidores? Indicador: La composición de la dirigencia nacional del partido se presenta como buen indicador de la representación partidaria. 
mientras que la representación es amplia, pues la composición de la dirigencia es representativa de grupos y minorías.

Las primeras dos tendencias organizacionales no son democráticas, en virtud de que concentran el poder en una persona o una élite reducida; en tanto que las tres siguientes son democráticas, pues distribuyen el poder entre un mayor numero de dirigentes, representantes o militantes. Ahora corresponde observar qué tipo de tendencia organizacional tuvo el PAN, por qué cambió su tendencia y hacia dónde ha sido dicho cambio.

\section{Partido de élite nacional: la concentración de poder en los fundadores (1939-1990)}

El PAN surge en 1939 y tiene en su génesis dos aspectos que lo marcaron por largo tiempo: el respeto a las reglas internas y la centralización del poder interno. Lo anterior fue logrado gracias al liderazgo e ideario de Manuel Gómez Morín, así como el contexto en el qué surge el partido. Aquí sólo resaltaré los dos últimos por razones de espacio.

Podemos resumir el ideario de Gómez Morín en los siguientes aspectos: 1) trabajo político que requiere de "hábitos y procedimientos de políticos profesionales", 2) la necesidad de organizar la actividad política para ser eficaz "de manera colectiva, de manera selectiva y de una manera duradera", 3) ante el triunfo electoral, "un grupo organizado en torno a convicciones comunes, no se basa en un hombre o en un movimiento espontáneo motivado por los valores negativos" (PRUD'HOMME, 1997, p. 5). A esto habría que agregar el énfasis en que las reglas coincidieran con la realidad, de ahí que se opusiera "a la política clientelar, caudillista, del país real. Proponía una política apegada al país formal" (REYNOSO, 2009, p. 45).

Una vez que Gómez Morín abandona la rectoría de la Universidad Nacional Autónoma de México (UNAM), la idea de un partido permanente y organizado seguía viva, pero "se necesitaba de una coyuntura electoral" (LUJAMBIO, 2009, p. 48). Esa coyuntura fue la compleja etapa final del gobierno de Lázaro Cárdenas (1939-1940), la cual se caracterizó por una polarización ideológica y política (GARCIADIEGO, 1999, p. 12-22). Todo esto haría propicio la reunión de distintos actores que tenían un nexo en común: Gómez Morín.

El origen diverso se reflejaría en el Consejo Nacional y el Comité Ejecutivo Nacional (CEN). Entre los grupos fundadores se encontraban: 1) universitarios, en los cuales había estudiantes y profesores; 2) líderes católicos que trascendían a la UNAM; 3) gente que no había participado antes en política con distintos orígenes (empresarios, abogados, etc.); y 4) ex revolucionarios que atendieron el llamado del nuevo partido.

Ahora bien, estos actores darían forma al Comité Directivo Nacional (CDN) y el Consejo Nacional. En cuanto al primer órgano Aminadab Pérez muestra que el $30 \%$ eran líderes católicos, el 26,6\% tenían un origen universitario, 
el 23,3\% eran empresarios y otros ciudadanos y el 3,3\% eran ex funcionarios y gente cercana a José Vasconcelos. En el Consejo Nacional el 25,88\% lo representaban universitarios, el 21,17\% eran empresarios y ciudadanos, el 15,29\% eran ex funcionarios y sólo 7,05\% eran líderes católicos (PÉREZ, 1999). Esto respalda la idea de que en la génesis predominaron universitarios y abogados, antes que católicos o empresarios (REYNOSO, 2009, p. 18).

En su primera asamblea del Consejo Nacional se aprobaron los primeros estatutos (PAN, 1990, p. 126 y 127). Con ello se materializó el ideario de Gómez Morín en torno a la necesidad de organizaciones estables y jerárquicas que, como se expondrá a continuación, dieron lugar a una tendencia organizacional caracterizada por dos cuestiones: 1) el irrestricto cumplimiento de los estatutos y 2) la centralización del poder.

\section{Participación}

La participación en la selección de candidato presidencial recayó en la Convención Nacional (1939-1988), mientras que en la selección de dirigencia nacional terminó en manos del Consejo Nacional (1939-1990). Aunque ambos electores cambiaron lentamente su integración.

En cuanto al candidato presidencial, habría que remarcar que los primeros seis candidatos (Efraín González Luna en 1952, Luis H. Álvarez en 1958, José González Torres en 1964, Efraín González Morfín en 1970, Pablo Emilio Madero en 1982 y Manuel Clouthier en 1988) fueron electos a través de la Convención Nacional, es decir, por no más de 10.000 personas, por ende se trató de procesos medianamente inclusivos, ya que eligieron los representantes de las diversas regiones. Y es que la Convención Nacional sufrió modificaciones en su integración, dando mayor inclusión a los estados en la medida de que el PAN tuvo mayor presencia organizativa en las entidades. Por ejemplo, en 1946 dicho órgano estaría integrado por delegaciones de los Comités Directivos Regionales (CDR) con cinco votos cada una y un adicional por cada quinientos mil habitantes de la entidad que representen. El CEN contaba con los mismos votos de la delegación más grande (PAN, 1946). En 1978-1979 se aumentaron a 30 más un por cada distrito electoral de la entidad correspondiente los votos de cada delegación de los CDR (PAN, 1980). En 1986 se incluyó a los miembros del Consejo Nacional y los presidentes de los Comités Directivos Municipales (CÁRDENAS, 1999).

En cuanto a la selección de dirigentes, han sido trece personas (Gómez Morín en 1939, Juan Gutiérrez Lascuráin en 1949, Alfonso Ituarte en 1956, José González Torres en 1958, Adolfo Christlieb en 1962, Ignacio Limón en 1968, Manuel González en 1969, José Á. Conchello en 1972, Efraín González Morfín en 1975, Manuel González en 1975, Abel Vicencio Tovar en 1978 y en 1981, Pablo Emilio Madero en 1984 y Luis H. Álvarez en 1987), hasta 1990, las que han sido electas por el Consejo Nacional, esto es por no más de 400 dirigentes y delegados; 
por lo cual se trató de procesos menos inclusivos que la selección de candidato presidencial. Ahora bien, el Consejo Nacional variaría lentamente su integración.

En 1939 el Consejo Nacional era "integrado por no menos de 30 ni más de 120 miembros" (PAN, 1939, p. 10). En 1962 se amplió el número de integrantes, quedando en no menos de 100 y no más de 200 integrantes (PAN, 1967). Con las reformas de 1971 no sólo el número de los integrantes, sino también su composición, ya que se incluyó en el Consejo Nacional a los dirigentes de los CDR, así como a "consejeros designados por la Asamblea General del Partido, en un número no menor de cien ni mayor que el número de distritos electorales federales" (PAN, 1971, p. 16 y 17). La última reforma a la integración del consejo, aprobada en 1979, determinó que se integraría por "los presidentes de los Comités Directivos Regionales (y) [...] doscientos Consejeros electos por la Asamblea" (PAN, 1980, p. 24).

Es así que tanto en la selección del candidato presidencial (Convención Nacional) como de dirigente nacional (Consejo Nacional), el elector se mantuvo estable; aunque con cambios en su número y sus componentes, debido al crecimiento organizativo del PAN en las entidades. La selección de candidato presidencial fue una decisión más inclusiva que la selección de dirigente, ya que fueron los representantes de los poderes estatales quienes eligieron, no la élite nacional en solitario.

\section{Competencia}

La selección de candidato presidencial fue competitiva en cuatro ocasiones $(1958,1964,1970$ y 1976) y poco competitiva en tres (1952, 1982 y 1988). En tanto que en la selección de dirigencia nacional, de doce personajes, solamente dos procesos serían competitivos (1975 y 1987), las demás se caracterizarían por votaciones mayoritarias. En los procesos competitivos existió más de una ronda de votación pues nadie obtendría la mayoría necesaria (80\%) por sí solo ${ }^{5}$.

\footnotetext{
${ }^{5}$ Por razones de espacio, sólo se observará lo referido a los procesos competitivos. Para tener mayor información sobre los demás procesos, véase trabajos citados anteriormente (REYNOSO, 2007; LOAEZA, 1999; LUJAMBIO, 2009).
} 
Tabla 1 - Resultados de las selecciones de candidato presidencial competitivas (1957-1975)

\begin{tabular}{|c|c|c|c|c|c|}
\hline Elección & \multicolumn{5}{|c|}{ Candidatos y votación } \\
\hline $\begin{array}{l}\text { 1957-Primera } \\
\text { ronda de } \\
\text { votación }\end{array}$ & $\begin{array}{l}\text { Preciado: } 10 \\
\text { votos }\end{array}$ & $\begin{array}{l}\text { Gutiérrez: } \\
18 \text { votos }\end{array}$ & $\begin{array}{c}\text { Castañeda: } 22 \\
\text { votos }\end{array}$ & $\begin{array}{l}\text { González: } \\
100 \text { votos }\end{array}$ & $\begin{array}{l}\text { Álvarez: } \\
178 \text { votos }\end{array}$ \\
\hline $\begin{array}{l}\text { 1957-Segunda } \\
\text { ronda de } \\
\text { votación }\end{array}$ & & & & $\begin{array}{l}\text { González } \\
\text { Torres: } \\
112 \text { votos }\end{array}$ & $\begin{array}{l}\text { Álvarez: } \\
215 \text { votos }\end{array}$ \\
\hline $\begin{array}{l}\text { 1963-Primera } \\
\text { ronda de } \\
\text { votación }\end{array}$ & Rosas: s/d* & $\begin{array}{l}\text { Christlieb: } \\
\text { s/d* }\end{array}$ & $\begin{array}{c}\text { González } \\
\text { Torres: s/d* }\end{array}$ & & \\
\hline $\begin{array}{l}\text { 1963-Tercera } \\
\text { ronda de } \\
\text { votación }\end{array}$ & & $\begin{array}{l}\text { Christlieb: } \\
32 \text { votos }\end{array}$ & $\begin{array}{l}\text { González } \\
\text { Torres: } \\
302 \text { votos } \\
\end{array}$ & & \\
\hline $\begin{array}{l}\text { 1969-Primera } \\
\text { ronda de } \\
\text { votación }\end{array}$ & $\begin{array}{l}\text { González } \\
\text { Morfín: } \\
210 \text { votos } \\
\end{array}$ & $\begin{array}{l}\text { Rosas: } \\
144 \text { votos }\end{array}$ & & & \\
\hline $\begin{array}{l}\text { 1969-Tercera } \\
\text { ronda de } \\
\text { votación }\end{array}$ & $\begin{array}{l}\text { González } \\
\text { Morfín: } \\
\text { obtiene el } \\
80 \%\end{array}$ & $\begin{array}{c}\text { Rosas: retira } \\
\text { su } \\
\text { candidatura }\end{array}$ & & & \\
\hline $\begin{array}{l}\text { 1975-Primera } \\
\text { ronda de } \\
\text { votación }\end{array}$ & $\begin{array}{l}\text { Madero: } \\
495 \text { votos }\end{array}$ & $\begin{array}{c}\text { Rosas: } \\
253 \text { votos }\end{array}$ & $\begin{array}{c}\text { Alarcón: } 93 \\
\text { votos. } \\
\text { Luego retira } \\
\text { su candidatura }\end{array}$ & & \\
\hline $\begin{array}{l}\text { 1975-Tercera } \\
\text { ronda de } \\
\text { votación }\end{array}$ & $\begin{array}{l}\text { Madero: } \\
449 \text { votos }\end{array}$ & $\begin{array}{c}\text { Rosas: } \\
390 \text { votos }\end{array}$ & & & \\
\hline $\begin{array}{l}\text { 1976-Luego de } \\
\text { cinco rondas de } \\
\text { votación }\end{array}$ & $\begin{array}{c}\text { Madero: } \\
\text { nunca } \\
\text { alcanzó el } \\
80 \% \\
\text { necesario }\end{array}$ & $\begin{array}{c}\text { Rosas: } \\
\text { nunca retiró } \\
\text { su } \\
\text { candidatura }\end{array}$ & & & \\
\hline $\begin{array}{l}\text { 1976-Séptima } \\
\text { ronda de } \\
\text { votación }\end{array}$ & $\begin{array}{c}\text { Madero: } \\
629 \text { votos. } \\
\text { No logró el } \\
80 \% * *\end{array}$ & $\begin{array}{c}\text { Rosas: } \\
228 \text { votos. } \\
\text { No retiró su } \\
\text { candidatura }\end{array}$ & & & \\
\hline
\end{tabular}

* Sin dato.

** La mayoría necesaria para nombrar candidato presidencial era del $80 \%$.

Fuente: Elaboración propia.

La tabla 1 muestra los resultados electorales de cada proceso competitivo. En la XIII Convención Nacional (noviembre de 1957) se dio el triunfo de un desconocido a nivel nacional (Luis H. Álvarez) frente al secretario general (José González), lo cual fue muestra de que en ese momento era mayoritaria la opinión hacia un cambio de estrategia en el PAN. 
Seis años más tarde, dentro de la XVII Convención Nacional (noviembre de 1963) se dio el enfrentamiento entre dos visiones: la política de diálogo impulsada por Adolfo Christlieb y la política de sus detractores encabezados por José González. Antes de la tercera ronda Christlieb dijo que no retiraría su candidatura, pero solicitaba votar por su contrincante. Así, González obtuvo triunfó, lo cual deja ver que la línea dialoguista no gozaba de gran apoyo.

En 1969 fue electo Efraín González Morfín dentro de la XXI Convención Nacional. El entusiasmo por la participación era amplio, ya que "los panistas estaban convencidos de que la política gubernamental hacia el movimiento estudiantil habría generado tales rencores contra el PRI, que los electores se lo cobrarían en las urnas" (LOAEZA, 1999, p. 298). Sobre todo después de los triunfos en Sonora y Mérida en 1967, por lo cual luego de dos rondas de votación, Salvador Rosas retiraría su candidatura y triunfaría González Morfín.

En 1975, como parte del conflicto entre el grupo de José Ángel Conchello y la dirigencia de Efraín González Morfín, se dio una competencia ríspida. Pese a que Pablo E. Madero siempre estuvo a la cabeza de las votaciones, nunca obtuvo el $80 \%$, por lo cual se canceló la Convención Nacional. En una segunda convención se intentó nombrar candidato presidencial, nuevamente, Madero estuvo a la cabeza en siete votaciones pero no obtuvo el $80 \%$. Su contrincante Salvador Rosas jamás retiro su candidatura, por lo cual el PAN se quedó sin candidato presidencial.

Tabla 2 - Resultados de las selecciones de dirigente nacional competitivas (1975 y 1987)

\begin{tabular}{c|c|c}
\hline Elección & \multicolumn{2}{|c}{ Candidatos y votación } \\
\hline $\begin{array}{c}\text { 1975-Luego de cinco } \\
\text { rondas de votación }\end{array}$ & $\begin{array}{c}\text { González Morfín: nunca } \\
\text { alcanzó el } 65 \% \text { necesario }\end{array}$ & $\begin{array}{c}\text { Conchello: retira su } \\
\text { candidatura }\end{array}$ \\
\hline $\begin{array}{c}\text { 1975-Sexta ronda de } \\
\text { votación }\end{array}$ & González Morfín: 124 votos & \\
\hline $\begin{array}{c}\text { 1987-Luego de dos } \\
\text { rondas de votación }\end{array}$ & $\begin{array}{c}\text { Álvarez: logra el } 66 \% \\
\text { necesario }\end{array}$ & $\begin{array}{c}\text { Madero: retira su } \\
\text { candidatura }\end{array}$ \\
\hline
\end{tabular}

* La mayoría necesaria para nombrar dirigente nacional era del 65\%.

Fuente: Elaboración propia.

La tabla 2 muestra los resultados de los procesos de selección de dirigentes competitivos, solamente los casos de 1975 y 1987 se caracterizaron por ser elecciones reñidas ${ }^{6}$. La elección de dirigencia nacional en la que resultó electo Efraín González Morfín, en marzo de 1975, fue una elección cuyo conflicto versó sobre la disyuntiva de participar o no en elecciones. Los dos contendientes fueron José Ángel Conchello (a favor de la participación electoral) y Efraín González Morfín (a favor de la abstención). El primero planteó una política de puertas abiertas a un electorado diverso para acoger el descontento contra el PRI, con

\footnotetext{
${ }^{6}$ Para mayor información de las restantes elecciones de dirigencia consúltese trabajos citados previamente (REYNOSO, 2007; LOAEZA, 1999).
} 
énfasis en la conquista del poder y la protesta; mientras que el segundo puso énfasis en la identidad y en redimir a la sociedad. Tras cinco rondas de votación Conchello retiró su candidatura, el hecho de que no se retirara antes mostraría la polarización existente.

La siguiente elección competitiva tuvo que esperar 12 años. En febrero de 1987 hubo una diferencia en términos estratégicos, pues Luis H. Álvarez buscaba radicalizarla (resistencia civil), mientras Pablo E. Madero planteaba medidas menos radicales (REYNOSO, 2009). Tras dos rondas de votación, Madero retiraría su candidatura y triunfaría Álvarez.

Así pues, se observa que los procesos de selección de candidato presidencial (cuatro de siete) han sido más competitivos que los de dirigente nacional (dos de doce). Aunque cuando la competencia se ha traducido en conflicto irreconciliable ha impactado en ambas (1975 y 1976). La poca competitividad de la selección de dirigente nacional es probable que se explique por el escaso crecimiento electoral de Acción Nacional, lo cual suponía que el dirigente no contaba con los recursos de poder que hicieran suficientemente atractiva la dirección del partido. En tanto que la competitividad en la candidatura presidencial se puede explicar ya que era la principal posición desde la cual el PAN podría dejar constancia de su oposición a los gobiernos priistas, aún a sabiendas de no tener opciones reales de arrebatarle la Presidencia de México.

\section{Representación}

El PAN es un partido que se ha caracterizado por no fomentar la creación de grupos organizados. Ante este hecho, haciendo propia la idea de "oleadas de panistas" de Bernardo Bátiz (REYNOSO, 2007, p. 260), es posible observar etapas en las cuales la conformación del CEN es dominada por miembros de tendencias ${ }^{7}$. En ese sentido, la élite fundadora es una tendencia integrada por los primeros miembros del partido o sus descendientes, los cuales son tradicionalistas y ortodoxos. Mientras que los neopanistas son desapegados de la doctrina y principios del PAN. En la etapa que va de 1939 a 1969 se encuentra presente la élite fundadora, mientras que en la etapa que va de 1972 a 1987 segunda se incluyen los neopanistas. Ahora bien, en ambas etapas existieron siete comités ejecutivos.

Para la etapa 1939-1969, se identificó que 17 personas dominaron el 35\% de los puestos del CEN; mientras que el restante 65\% corresponde a 93 personas. Es decir, la tercera parte del comité estuvo en manos de 17 personas, entre los cuales se encontraban integrantes de la élite fundadora, entre ellos cuatro ex dirigentes como: Gómez Morín, Manuel González, Adolfo Christlieb, Alfonso Ituarte, Rafael Preciado y Manuel Ulloa, entre otros. Ocuparon 75 lugares de 215

\footnotetext{
${ }^{7}$ Se recomienda al lector observar la clasificación inicial de Giovanni Sartori en donde ubica a las facciones como un grupo específico de poder, en tanto que la tendencia es un conjunto establecido de actitudes (SARTORI, 1980).
} 
posibles, lo cual deja ver la concentración en este periodo en manos de élite fundadora.

Para la etapa de 1972-1987, se observó que 18 personas dominaron el $47,99 \%$ de los puestos en el comité; mientras que el restante $52,1 \%$ corresponde a 88 personas. Casi la mitad del CEN estuvo en manos de 18 personas, entre los cuales se encuentran neopanistas que en 1992 abandonarían el partido, como: Bernardo Bátiz, Jesús González Schmal y José González. Aunque también estarían representantes de la élite fundadora como: Juan Manuel Gómez Morín y Rafael Preciado. Esto permite afirmar que no existió un desplazamiento completo de la élite fundadora, aunque significó la entrada de nuevos panistas al CEN. Las 18 personas ocuparon 88 lugares de 184 posibles, lo cual deja ver la centralización en este periodo en manos de neopanistas, en mayor medida, y representantes de la élite fundadora.

Así pues, de 1939 a 1969 se observa un dominio de la élite fundadora, mientras que de 1972 a 1987 existe dominio de los neopanistas, pero con presencia de la élite fundadora. Si bien no hubo un desplazamiento completo de los fundadores, por el ingreso de los neopanistas, como vimos en el apartado anterior, dicha situación condujo a conflictos importantes por la selección de dirigente nacional (1975) y candidato presidencial (1976).

\section{Crecimiento electoral: nuevas exigencias de cambio}

El crecimiento electoral que el PAN experimentó en los noventa (que concluye con el triunfo del año 2000), trajo consigo una serie de retos internos: tensiones entre la dirección nacional y los poderes estatales y, posteriormente, entre el gobierno y el partido. Esto modificó la tendencia organizacional que prevaleció de 1939 a inicios de los noventa. El crecimiento electoral del PAN a nivel estatal (1989-1994) potencializó a los estados, y la llegada al gobierno federal (2000) complicaría aún más la situación interna. La Tabla 3 ejemplifica dicho crecimiento. 
Tabla 3 - Crecimiento del PAN en los noventa

\begin{tabular}{|c|c|c|c|c|c|c|c|c|c|c|c|}
\hline & 1988 & 1989 & 1990 & 1991 & 1992 & 1993 & 1994 & 1996 & 1997 & 1999 & 2000 \\
\hline $\begin{array}{c}\text { Población } \\
\text { gobernada por } \\
\text { el PAN }(\%)\end{array}$ & 0,8 & 3,5 & 5,1 & 10,1 & 12,6 & & 15,5 & 24,4 & 38,5 & 34,8 & 41,4 \\
\hline $\begin{array}{c}\text { Presidentes } \\
\text { municipales } \\
\text { panistas }\end{array}$ & 17 & 29 & 35 & 49 & 98 & 99 & 128 & 223 & 292 & 287 & 306 \\
\hline $\begin{array}{c}\text { Gobernadores } \\
\text { panistas }\end{array}$ & 0 & 1 & 1 & 1 & 2 & 3 & 3 & 4 & 4 & 4 & 9 \\
\hline Senadores & 0 & & & 1 & & & 25 & & 31 & & 46 \\
\hline $\begin{array}{l}\text { Diputados } \\
\text { Federales }\end{array}$ & 101 & & & 89 & & & 119 & & 121 & & 207 \\
\hline $\begin{array}{c}\text { Presidencia de } \\
\text { México }(\%)\end{array}$ & 17,1 & & & & & & 25,9 & & & & 42,5 \\
\hline
\end{tabular}

Fuente: Elaboración propia.

Como apunta Víctor Reynoso, en sus primeros cincuenta años de vida (1939-1989) el PAN nunca ganó una gubernatura, jamás obtuvo la mayoría de algún congreso local y nunca estuvo ni siquiera cerca de obtener la Presidencia de México. Así pues, el triunfo de Vicente Fox "fue la última vuelta de tuerca en este proceso de cambio en el que el PAN dejó de ser un partido de oposición y pasó a ser un partido que comparte el poder" (REYNOSO, 2009, p. 57). Este crecimiento al exterior e interior le significó retos y tensiones internas, tal como dar cabida a nuevos liderazgos estatales, de gobierno y militantes. A ello respondió el cambio en la tendencia organizacional de mediados de los noventa y principios del siglo XXI. A continuación veremos cuál es la nueva tendencia organizacional donde el principal ingrediente son diversos actores: las funciones de gobierno, los poderes estatales y la dirigencia nacional.

\section{Partido de élite ampliado: la distribución de poder entre los estados, los gobiernos y el partido (1993-2012)}

El PAN ha transitado de una situación donde la élite nacional (integrada por los fundadores $\mathrm{y}$, desde los setenta, incluidos los neopanistas) dominó gran parte de sus procesos internos de manera, a una donde diversos actores (élite nacional, poderes estatales y funciones de gobierno) toman las decisiones. Así pues, la estructura centralizada del PAN a lo largo del tiempo fue dando mayor peso a los estados y, después, al gobierno. En su momento generó una pugna entre los poderes estatales y la dirigencia nacional que se hizo evidente una vez que el partido logró obtener triunfos electorales importantes. Luego, cuando el PAN 
obtuvo la Presidencia de México la pugna fue entre el gobierno y el partido. Lo anterior, varió la tendencia organizacional.

\section{Participación}

Al candidato presidencial lo eligió por última vez la Convención Nacional en 1994, en dicha convención las delegaciones estatales crecerían de acuerdo con su peso electoral. Posteriormente, el PAN decidiría elegir a su candidato a través de la militancia (2006), a veces acompañada de los adherentes (1999 y 2012). En tanto que al dirigente nacional lo elige el Consejo Nacional que ha complejizado su composición interna al dar cabida a los estados con base en sus réditos electorales.

Con las reformas estatutarias de 1992 las delegaciones dentro de la Convención Nacional pasarían a 15 votos, más un voto adicional por cada fracción superior al $0,5 \%$ de la votación total emitida en la entidad haya obtenido el partido en la última elección federal para diputados; así como otro voto fracción superior al $0,5 \%$ de la votación nacional del partido, que corresponda a la entidad, obtenida en la elección referida (PAN, 1992). Este último cambio fue fruto de los éxitos electorales del PAN. La convención elegiría por última vez al candidato presidencial del PAN en 1994, dicha decisión medianamente inclusiva recaería en Diego Fernández de Cevallos.

Posteriormente, surgirían los cuestionamientos respecto a que la nominación presidencial fuera decidida por la convención. En 1998, debido a que no contaba con la simpatía de la dirigencia en turno, Vicente Fox decidió crear un organismo externo al partido (Amigos de Fox) que le permitiera promover su imagen y rebasar la capacidad decisoria de la dirigencia. Así, frente a la dirigencia se presentaba el dilema de: a) efectuando primarias Fox aseguraba el triunfo, o b) cerrarse a la Convención Nacional lo que, significaba tener un proceso menos democrático que el PRD y el PRI, tampoco aseguraba evitar la candidatura de Fox. Así pues, pesaría más el llamado "efecto de imitación" respecto a lo realizado por el PRD y el PRI, con el objetivo de "mejorar su imagen ante la opinión pública" (ALARCÓN y FREIDENBERG, 2007, p. 739). Por ende, en octubre de 1998 el Consejo Nacional decidió abrir el proceso a militantes y adherentes con seis meses de militancia, lo cual fue ratificado en la Asamblea Nacional de mayo de 1999.

Luego del triunfo del año 2000, el PAN iniciaría un proceso de reformas a los estatutos, con las cuales se le quitaría a los adherentes el derecho de votar por el candidato presidencial (PAN, 2001). El cambio duraría poco, debido a que con las reformas estatutarias de 2004 se devolvería dicho derecho a la adherencia del PAN. En 2008 y 2011 no variaría nada de lo anterior. Por lo cual, se ha tratado de decisiones inclusivas.

En cuanto a la participación dentro de la elección de dirigente nacional, como bien apunta Víctor Reynoso llama la atención que la selección siga siendo 
la misma desde 1939, es decir a través del Consejo Nacional (2009). Aunque es preciso indicar que ha cambiado el tamaño y conformación del Consejo Nacional. Lo anterior tuvo que ver indirectamente con el crecimiento electoral de los estados.

Con las reformas de 1992 se modificó la integración del Consejo Nacional, a partir de ahí estaría integrado por el presidente y secretario general del CEN, los ex presidentes del CEN, los presidentes de los Comité Directivo Estatal (CDE), los coordinadores parlamentarios, el coordinador nacional de los diputados locales y doscientos cincuenta consejeros electos por Asamblea Nacional (PAN, 1992). Con esto se dio ingreso a los dirigentes de los CDE, los coordinadores parlamentarios (funciones de gobierno) y los ex presidentes del CEN (órganos ejecutivos). Además se premiaría a los estados de acuerdo con su éxito electoral ${ }^{8}$.

Producto de las reformas de 2001 se aumentó a 300 el número de consejeros nombrados por la Asamblea Nacional, al tiempo que se agregaría al Presidente de México (funciones de gobierno) y a los gobernadores (poderes estatales) como integrantes del Consejo Nacional.

Las reformas de 2008 modificaron la composición del consejo, ya que se agregaría al coordinador nacional de ayuntamientos y a los miembros activos del partido que hayan sido consejeros nacionales por 20 años o más (PAN, 2008).

Se observa que la participación en la selección de candidato presidencial se modificó de ser la Convención Nacional (1994) el elector a ser la militancia acompañada de los adherentes (1999 y 2012) o en solitario (2006). El PAN, antes que optar por la democracia, decidió un proceso que lo legitimara ante la ciudadanía y le diera mayor éxito electoral. Aún así no es de despreciarse que la militancia ejerza influencia en esta decisión. En cuanto a la selección de dirigente nacional, el cambio fue sutil, pues se amplió la representación del encargado de elegir al dirigente, agregando a los estados (dirigentes de los comités estatales y propuestas con base en su votación), a los órganos ejecutivos (ex presidentes del CEN) y deliberativos (consejeros nacionales con más de 20 años de militancia) y a las funciones de gobierno del partido (Presidente de México, coordinadores parlamentarios, gobernadores y coordinador nacional de ayuntamientos).

\section{Competencia}

La selección de candidato presidencial de 1994 a 2012 no fue competitiva ya que los resultados entre el triunfador y los derrotados fueron amplios; sin

\footnotetext{
${ }^{8}$ Respecto a los 250 consejeros fueron propuestos de la siguiente forma. Mediante Asamblea, los estados tendrán derecho a proponer candidatos con base en la votación obtenida en la entidad en la última elección federal para diputados (un del 2,5\% al 10\%; dos de más de $10 \%$ y hasta promedio nacional; y tres con más del promedio nacional). Asimismo tendrán derecho a presentar un candidato por cada $0,33 \%$ obtenido en la entidad, de la votación nacional del partido. El CEN por su parte, tendría derecho a proponer hasta el 10\% del total de propuestas (PAN, 1992, p. 12). Con esto se premiaría a los estados con mayor votación, pues tendrían derecho a mayores propuestas de consejeros nacionales y, por tanto, mayor peso en la elección del dirigente nacional.
} 
embargo, hubo contrincantes que enarbolaban un conflicto entre los poderes estatales y la dirigencia nacional (1994) y entre el gobierno y el partido (2006 y 2012), los cuales vale la pena retomar. En tanto que en la selección de dirigencia nacional, el conflicto por las relaciones con el gobierno federal (1990), entre los poderes estatales y la dirigencia nacional (1993 y 1996), y entre gobierno y partido (2002, 2005 y 2010) estuvieron presentes.

En cuanto a la selección de candidato presidencial, la elección de Diego Fernández de Cevallos no fue un proceso competitivo ya que triunfó en la primera ronda de votación (64,71\%), empero tuvo tras de sí el conflicto entre los poderes estatales y la dirigencia nacional. Fernández de Cevallos defendía el diálogo y negociación con el gobierno, frente a él se presentaron dos dirigentes estatales de recién ingreso al partido: Adalberto Rosas de Sonora y Javier Livas de Nuevo León, este último planteaba no aceptar las "migajas de poder" de las negociaciones con el gobierno federal del PRI.

Después del año 2000, los siguientes procesos de selección de candidato presidencial presentaron una situación novedosa ya que el PAN detentaba la Presidencia de México. A partir de ahí se dio una relación autónoma y, por momentos conflictiva, entre el partido y el gobierno. En 2006 participaron tres candidatos, Santiago Creel, Felipe Calderón y Alberto Cárdenas. El primero tenía mayor simpatía en la población en general y era apoyado por el presidente Vicente Fox. El segundo contaba con mayor apoyo entre militantes panistas. Al final Calderón triunfó con una ventaja cercana al 12\% frente a Creel.

En 2012 los candidatos serían Ernesto Cordero, Josefina Vázquez Mota y Santiago Creel. El primero apoyado por el titular del Ejecutivo Federal, la segunda con apoyo de grupos regionales y el partido. Al final se declararía el triunfo de Vázquez Mota con el 55\% de la votación, frente al 38,1\% de Cordero y 6,1\% de Creel. Tanto en 2006 como en 2012 perdió el candidato del Presidente de México.

En cuanto a la selección de dirigentes nacionales, han sido ocho los personajes nombrados de 1990 a 2010, dichos procesos han sido competitivos, salvo los casos de 1999 (Luis Felipe Bravo), 2007 (Germán Martínez) y 2009 (César Nava). Las elecciones competitivas pueden explicarse por las relaciones con el nuevo gobierno (1990), la pugna entre los poderes estatales y la dirigencia nacional (1993 y 1996) y la del gobierno frente al partido (2002, 2005 y 2010). 
Tabla 4 - Resultados de las selecciones de dirigente nacional competitivas (1988-2010)

\begin{tabular}{|c|c|c|c|c|c|}
\hline Elección & \multicolumn{5}{|c|}{ Candidatos y votación } \\
\hline $\begin{array}{l}\text { 1988-Luego de } \\
\text { cuatro rondas } \\
\text { de votación }\end{array}$ & $\begin{array}{c}\text { Álvarez: } \\
\text { consigue } 66 \%\end{array}$ & $\begin{array}{l}\text { Jiménez: } \\
\text { nunca } \\
\text { retira su } \\
\text { candidatura }\end{array}$ & & & \\
\hline $\begin{array}{l}\text { 1993-Primera } \\
\text { ronda de } \\
\text { votación }\end{array}$ & $\begin{array}{l}\text { Castillo: } \\
89 \text { votos }\end{array}$ & $\begin{array}{l}\text { Ling: } \\
62 \text { votos }\end{array}$ & $\begin{array}{l}\text { Elizondo: } \\
47 \text { votos }\end{array}$ & & \\
\hline $\begin{array}{l}\text { 1993-Segunda } \\
\text { ronda de } \\
\text { votación }\end{array}$ & $\begin{array}{l}\text { Castillo: } \\
98 \text { votos }\end{array}$ & $\begin{array}{l}\text { Ling: } \\
101 \text { votos }\end{array}$ & & & \\
\hline $\begin{array}{l}\text { 1993-Tercera } \\
\text { ronda de } \\
\text { votación }\end{array}$ & $\begin{array}{l}\text { Castillo: } \\
107 \text { votos }\end{array}$ & $\begin{array}{c}\text { Ling: } \\
90 \text { votos. } \\
\text { Retira su } \\
\text { candidatura }\end{array}$ & & & \\
\hline $\begin{array}{l}\text { 1993-Cuarta } \\
\text { ronda de } \\
\text { votación }\end{array}$ & $\begin{array}{c}\text { Castillo: } \\
\text { obtiene 66\% }\end{array}$ & & & & \\
\hline $\begin{array}{l}\text { 1996-Primera } \\
\text { ronda de } \\
\text { votación }\end{array}$ & $\begin{array}{l}\text { Calderón: } \\
159 \text { votos }\end{array}$ & $\begin{array}{c}\text { Ruffo: } \\
107 \text { votos. } \\
\text { Retira su } \\
\text { candidatura }\end{array}$ & & & \\
\hline $\begin{array}{l}\text { 1996-Segunda } \\
\text { ronda de } \\
\text { votación }\end{array}$ & $\begin{array}{c}\text { Calderón: } \\
\text { obtiene } 66 \%\end{array}$ & & & & \\
\hline $\begin{array}{l}\text { 2002-Primera } \\
\text { ronda de } \\
\text { votación }\end{array}$ & $\begin{array}{c}\text { Bravo Mena: } \\
152 \text { votos }\end{array}$ & $\begin{array}{c}\text { Medina: } \\
\text { 124 votos. } \\
\text { Retira su } \\
\text { candidatura }\end{array}$ & & & \\
\hline $\begin{array}{l}\text { 2002-Segunda } \\
\text { ronda de } \\
\text { votación }\end{array}$ & $\begin{array}{l}\text { Bravo mena: } \\
\text { logra el } 66 \%\end{array}$ & & & & \\
\hline $\begin{array}{l}\text { 2005-Primera } \\
\begin{array}{l}\text { ronda de } \\
\text { votación }\end{array} \\
\end{array}$ & $\begin{array}{l}\text { Espino: } \\
158 \text { votos }\end{array}$ & $\begin{array}{l}\text { Medina: } \\
148 \text { votos }\end{array}$ & $\begin{array}{l}\text { Rodríguez: } \\
42 \text { votos }\end{array}$ & $\begin{array}{l}\text { Zapata: } \\
26 \text { votos }\end{array}$ & \\
\hline $\begin{array}{l}\text { 2005-Segunda } \\
\text { ronda de } \\
\text { votación }\end{array}$ & $\begin{array}{l}\text { Espino: } \\
196 \text { votos }\end{array}$ & $\begin{array}{c}\text { Medina: } \\
174 \text { votos. } \\
\text { Retiro su } \\
\text { candidatura }\end{array}$ & & & \\
\hline $\begin{array}{l}\text { 2005-Tercera } \\
\text { ronda de } \\
\text { votación } \\
\end{array}$ & $\begin{array}{c}\text { Espino: } \\
\text { obtuvo el } 66 \%\end{array}$ & & & & \\
\hline $\begin{array}{l}\text { 2010-Primera } \\
\text { ronda de } \\
\text { votación }\end{array}$ & $\begin{array}{c}\text { Gil: } \\
122 \text { votos. } \\
\text { Retira su } \\
\text { candidatura }\end{array}$ & $\begin{array}{l}\text { Madero: } \\
129 \text { votos }\end{array}$ & $\begin{array}{l}\text { Romero: } \\
57 \text { votos }\end{array}$ & $\begin{array}{l}\text { Díaz: } \\
14 \text { votos }\end{array}$ & $\begin{array}{l}\text { Ramírez: } \\
45 \text { votos }\end{array}$ \\
\hline $\begin{array}{l}\text { 2010-Segunda } \\
\text { ronda de } \\
\text { votación }\end{array}$ & & $\begin{array}{c}\text { Madero: } \\
\text { obtiene el } \\
66 \%\end{array}$ & & & \\
\hline
\end{tabular}

* La mayoría necesaria para nombrar dirigente nacional era de $66 \%$.

Fuente: Elaboración propia. 
La elección de 1988, el desplazamiento del PAN como principal fuerza opositora y el nacimiento del PRD provocaron que la radicalidad de la dirigencia de Luis H. Álvarez se moderara, lo cual generó conflictos al interior del PAN. La contienda de 1990 tendría de un lado a Álvarez buscando su reelección y defendiendo el diálogo con el gobierno federal; del otro lado estaba el grupo opositor, posteriormente conocidos como los foristas, que postuló a Gabriel Jiménez, planteando transparentar las relaciones con el gobierno federal. Finalmente, Álvarez ganó en la cuarta ronda de votación. El hecho de que Jiménez no retirara su candidatura mostró la polarización existente.

En 1993 la tensión se dio entre los poderes estatales y la dirigencia nacional, pues los primeros comenzaban a demandar mayor representación en el CEN y mayor libertad de maniobra en la elección de candidatos; para ellos el CEN era una copia fiel "del autoritarismo centralista que tanto se les reprochaba al gobierno federal y al PRI, y asimismo criticaban la centralización de los cargos de elección" (LOAEZA, 1999, p. 516). Del otro lado, Carlos Castillo enarbolaba la doctrina panista, al tiempo que defendía las relaciones con el gobierno federal. Participaron Alfredo Ling (apoyado por los líderes locales como Vicente Fox y Francisco Barrio) y Rodolfo Elizondo. En la cuarta ronda de votación triunfaría Castillo.

En 1996 compitieron Felipe Calderón y Ernesto Ruffo. El segundo representaba la posibilidad de una descentralización en el PAN enarbolada por los panistas que tuvieron éxito en estados como Baja California, Chihuahua, Guanajuato y Nuevo León; mientras que Calderón representaba una vuelta a las tradiciones en el PAN. El triunfo de Calderón se debió a que los neopanistas, si bien habían ganado un gran número de funciones de gobierno en los noventa, no tenían el dominio de la estructura interna del partido, y era precisamente en esa estructura donde se elegiría al presidente del partido. Así, Calderón triunfaría en una segunda votación.

En la elección de 2002 el conflicto fue entre partido y gobierno. De lado de Luis Felipe Bravo estaban quienes marcaban distancia "de un gobierno al que consideraban poco representativo del PAN", mientras que de lado de Carlos Medina se encontraban quienes creían que era momento de ser un acompañante del gobierno de Vicente Fox (HERNÁNDEZ, 2005, p. 174). En la segunda ronda de votación triunfaría la primera postura.

Para 2005 contendieron Juan José Rodríguez, Alejandro Zapata, Manuel Espino y Carlos Medina. Los dos últimos eran los contendientes más fuertes. Medina era el candidato de unidad de los precandidatos presidenciales Felipe Calderón y Francisco Barrio y de sectores tradicionales del partido. Del otro lado, Manuel Espino era apoyado por el precandidato Santiago Creel y el presidente Vicente Fox (ALARCÓN y FREIDENBERG, 2007, p. 745). En la tercera ronda de votación triunfaría el candidato apoyado por Fox. 
A finales del 2010 se presentaron las candidaturas de Cecilia Romero, Blanca Díaz, Francisco Ramírez, Roberto Gil y Gustavo Madero. La contienda se definió entre los dos últimos. Gil era el candidato del Presidente, Madero de la élite nacional y Ramírez de los poderes estatales. El apoyo de sectores tradicionales en el Consejo Nacional dio el triunfo a Madero en la segunda ronda de votación.

Así pues, los procesos de selección de candidato presidencial estuvieron atravesados por la pugna entre los poderes estatales y la dirigencia nacional (1994) y el conflicto entre el gobierno y el partido (2006 y 2012). Aún así no fueron competitivos, ya que si bien los estados fueron ganando peso en la convención no fue lo suficiente para lograr procesos competitivos (1994). En tanto que la intromisión del Presidente de México no fue bien vista por los militantes, fieles a su idea de que prevalezca lo formal sobre lo informal. Mientras que la selección de dirigencia nacional los procesos competitivos fueron impulsados por tres conflictos: 1) el desatado por las relaciones con el gobierno federal (1990), 2) el existente entre los poderes estatales y la dirigencia nacional (1993 y 1996), y 3) el que se suscitó entre el gobierno contra el partido (2002, 2005 y 2010). Lo anterior, deja ver que el peso de los poderes estales en el Consejo Nacional fue mayor que en la Convención Nacional, en tanto que el Presidente de México logró imponer a su candidato en una ocasión (2005).

\section{Representación}

En este periodo los CEN se integraron por miembros de la élite, de los estados y del gobierno federal. Habiendo dos etapas, de 1990 a 1999 se dio cabida a los poderes estatales, y después del 2000 se hizo lo propio con el gobierno federal. De 1990 a 1999 existieron tres CEN, mientras que de 2002 a 2012 existieron cinco.

En la primera etapa 17 personas dominan el $41 \%$ de los puestos en los comités. Mientras que el restante $(59 \%)$ corresponde a 59 personas. La cuarta parte del CEN estuvo en manos de 17 personas, entre las cuales se encontrarían integrantes de los estados (liderazgos y funciones de gobierno estatales) como Juan Antonio García (Coahuila), Juan Miguel Alcántara (Guanajuato), Federico Ling (Durango), Juan de Dios Castro (Durango), Ricardo García Cervantes (Coahuila), Tarciso Rodríguez (Jalisco) y Salvador Beltrán del Río (Chihuahua), entre otros. También es importante decir que se encontrarían dirigentes de viejo cuño como: Diego Fernández de Cevallos, Felipe Calderón, Juan Manuel Gómez Morín, Luis H. Álvarez, María E. Álvarez, Carlos Castillo y Cecilia Romero. Concentraron un total de 50 lugares de 145 posibles.

En la segunda etapa (2002-2013) 16 personas dominan el 28\% de los espacios del CEN; mientras que el restante $72 \%$ corresponde a 120 personas. Poco más de la cuarta parte del comité estuvo en manos de 17 personas, entre los cuales se encuentra gente cercana al Ejecutivo Federal como Beatriz Zavala, César Nava 
y Mariana Gómez del Campo. También destacan liderazgos estatales como Jorge Ocejo (Puebla), Esmeralda Cárdenas (Colima), Gustavo Madero (Chihuahua), Marco Antonio Adame (Gobernador de Morelos de 2006 a 2012), Teresa Ortuño (Coahuila) y Ricardo García Cervantes (Coahuila). Y, con menos presencia, gente de viejo cuño como María E. Álvarez y Cecilia Romero. Estas 17 personas concentraron 56 lugares de 198 posibles.

Así pues, de 1990 a 2000 existió un dominio de los poderes estatales y la élite nacional, mientras que de 2000 a 2012 se agregaron, a estos actores, miembros cercanos al gobierno federal. En el caso de los poderes estatales se trató de la inclusión de actores con base en su éxito electoral, mientras que en el caso del gobierno federal se trató de acercar al partido al gobierno en turno, sobre todo en el sexenio de 2006-2012, para evitar las confrontaciones suscitadas en el sexenio anterior (2000-2006).

\section{A manera de cierre}

El PAN ha transitado de una situación donde la élite nacional (integrada por los fundadores y, desde los setenta, los neopanistas) dominó gran parte de sus procesos internos de manera formal (participación, competencia y representación), a una donde diversos actores (partido, poderes estatales y funciones de gobierno) dominan dichos procesos.

Dicho cambió tuvo que ver con los triunfos electorales del PAN en la década de los noventa. La llegada a la Presidencia de México fue el punto de llegada a una nueva situación en la cual se incorporarían nuevos actores en la toma de decisiones. Fue un proceso de adaptación a las nuevas realidades (ser partido gobernante), antes que un proceso de democratización orquestado desde adentro.

Resulta natural que en la segunda tendencia la selección de dirigente nacional fuera más competitiva que en la primera, debido a que para entonces poseer la dirigencia nacional suponía recursos que antaño, en el sistema de partido hegemónico, eran inexistentes debido a la posición marginal del partido.

Por otro lado, la selección de candidato presidencial se volvió una decisión menos competitiva que antaño, lo cual tendría que ver con la intervención de actores informales como el Presidente de México, lo cual no sería muy bien visto por los panistas y ayudaría a lograr un resultados desfavorables al candidato del Presidente en turno. La aglutinación contra el candidato del Presidente de México fue congruente con la idea de que prevaleciera lo formal (estatutos) sobre lo informal.

En cuanto a la conformación del CEN, era bastante natural que se diera cabida a los poderes estatales (1990-2000), pues ellos eran quienes habían logrado los triunfos electorales, por lo cual exigían participar en la toma de decisiones. Cuando Acción Nacional gana la Presidencia de México, se dio un periodo de autonomía y enfrentamiento entre el partido y el gobierno (2000-2006) y un 
segundo periodo de mayor colaboración que se visualiza con la presencia de actores cercanos a la Presidencia en el CEN (2006-2012).

Como se esperaba, las tendencias encontradas no son tipos puros presentes en la realidad, sino más bien híbridos. Si se observa con detenimiento la primera etapa del PAN tuvo características de partido de élite nacional (conformación del CEN, poca inclusividad en dirigencia y competencia entre la élite), partido representativo (inclusividad en candidato presidencial). No obstante, en suma, dominó la élite nacional. Mientras que la segunda etapa tuvo características de partido de élite nacional (poca inclusividad en dirigencia), partido de élites ampliado (competencia y conformación del CEN) y partido de bases (inclusividad en candidato presidencial). En suma dominaron varios actores (partido, gobierno y poderes estatales).

Aún así las tendencias organizacionales ayudaron a caracterizar la democracia interna del PAN. En suma, el partido ha distribuido en mayor medida su poder interno, si comparamos al partido con élite nacional con el partido de élite ampliado, tipos ideales a los cuales más se aproxima la evolución del PAN. La primera es una tendencia no democrática y la segunda es democrática. Aunque su evolución sigue siendo reducida si lo comparamos con el caso ideal del partido con democracia de bases.

En julio de 2012 Acción Nacional perdió la Presidencia de México, lo cual ha llevado al partido a enfrentamientos entre gente cercana al ex titular del Ejecutivo Federal y la élite nacional que apoyó a Gustavo Madero en la selección de dirigente de 2010. Digerir la derrota electoral ha costado bastante tiempo y esfuerzo al PAN, ya que sus conflictos recientemente se han extendido a la arena legislativa con la destitución del coordinador de los senadores (Ernesto Cordero) afín a Calderón (mayo, 2013).

Acción Nacional ha entrado a una etapa de turbulencia interna, esto dará lugar a una nueva distribución de poder, la cual ya se encuentra en marcha. Recientemente, el PAN decidió, en aras de legitimarse ante la ciudadanía, quitarle la facultad de seleccionar al dirigente al Consejo Nacional y dársela a la militancia (marzo, 2013). El cambio en torno a la democracia interna parece incierto, pero la estabilidad (de reglas y procesos) del partido no proporciona pistas sobre un posible cambio abrupto. Lo más probable es que, en aras de sobrevivir organizativamente, el partido se aferre a los centros de poder existentes (élite nacional y poderes estatales), una vez que termine el ajuste de cuentas con el ex titular del Ejecutivo Federal.

\footnotetext{
Alberto Espejel Espinoza é Licenciado em Ciência Política e Administração Pública pela Universidad Nacional Autónoma de México (UNAM). Mestre em Ciências Sociais pela Facultad Latinoamericana de Ciencias Sociales, sede México e Doutorando em Ciência Política pela UNAM. E-mail: alberto.espejel.espinoza@gmail.com
} 


\section{Referencias}

ALARCÓN, Víctor; FREIDENBERG, Flavia. El proceso de selección del candidato presidencial el PAN en 2005. Revista Mexicana de Sociología, Coyoacán, v. 69, n. 4, p. 729-770, oct.-dic. 2007.

CÁRDENAS, Jaime. Democracia interna y métodos de selección de candidatos y dirigentes en el PAN. Propuesta, Cidade do México, v. II, n. 8, p. 47-97, feb. 1999.

FREIDENBERG, Flavia. ¿Qué es la democracia interna? In: REYNOSO, José; SÁNCHEZ DE LA BARQUERA, Herminio (comps.). Estudios en homenaje a Dieter Nohlen en su septuagésimo aniversario. México: IIJ-UNAM, 2009. p. 227-295.

GARCIADIEGO, Javier. La oposición de las clases media al cardenismo: contexto en el que nace Acción Nacional. Propuesta, Cidade do México, v. 1, n. 8, p. 9-35, feb. 1999.

HERNÁNDEZ, Tania. Paradojas, acuerdos y contradicciones: El Partido Acción Nacional. In: REVELES, Francisco (comp.). Los partidos políticos en México. ¿Crisis, adaptación o transformación? México: UNAM, 2005. p. 165-186.

LOAEZA, Soledad. El Partido Acción Nacional: la larga marcha, 1939-1994. Oposición leal y partido de protesta. México: FCE, 1999.

LUJAMBIO, Alonso. La democracia indispensable: Ensayos sobre la historia del Partido Acción Nacional. México: DGE/ Equilibrista, 2009.

MICHELS, Robert. Los partidos políticos: Un estudio sociológico de las tendencias oligárquicas de la democracia interna. Tomo I y II. Buenos Aires: Amorrortu, 1983.

NAVARRO, José. Partidos políticos y "democracia interna". Madrid: Centro de Estudios Políticos y Constitucionales, 1999.

OSTROGORSKI, Moisei. Democracy and the organization of political parties. Volume I: England. London: Transaction Books, 1982.

PAN. Partido Acción Nacional. Estatutos. México: PAN, 1939. . Partido Acción Nacional. Estatutos. México: PAN, 1946. . Partido Acción Nacional. Estatutos. México: PAN, 1967. . Partido Acción Nacional. Estatutos. México: PAN, 1971. . Partido Acción Nacional. Estatutos. México: PAN, 1980.

1990.

Partido Acción Nacional. Así nació Acción Nacional, México: PAN, Partido Acción Nacional. Estatutos Generales. México: PAN, 1992. . Partido Acción Nacional. Estatutos. México: PAN, 2001. . Partido Acción Nacional. Estatutos. México: PAN, 2008.

PÉREZ, Aminadab. Raíces históricas del Partido Acción Nacional. Propuesta, Cidade do México, v. 1, n. 8, p. 36-68, feb. 1999.

PRUD'HOMME, Jean-Francoise. The Nacional Action Party's. Organization life an strategic decisions. Documentos de trabajo. CIDE, n. 59, p. 1-32, 1997. 
REVELES, Francisco. PAN: Los signos de la institucionalización. México: Gernika, 2002.

. La propuesta y el candidato: El PAN hacia las elecciones presidenciales de 2006. Revista Imaginales, Hermosillo, n. 3, p. 39-58, ene.-jul. 2005.

REYNOSO, Víctor. Rupturas en el vértice. El PAN a través de sus escisiones históricas. México: CEPCOM, 2007. . El Partido Acción Nacional, México: Nostra Ediciones, 2009.

SARTORI, Giovanni. Partidos y sistemas de partidos. Madrid: Alianza, 1980.

SCARROW, Susan. Political parties and democracy in theorethical and practical perspectives. Implementing intra-party democracy. Washington: National Democratic Institute for International Affairs, 2005.

Texto recebido em 05 de abril de 2013. Aprovado em 24 de julho de 2013. 